Poppy Rahayu', Annisya Pramesti' ${ }^{2}$, Aulia Dwi ${ }^{3}$, Syifa Fauziah $^{4}$

1,2,3,4 Japanese Education Program, Arts and Linguistic Science, Universitas Negeri Jakarta

Jalan Rawamangun Muka, RT.11/RW.14 Rawamangun, Pulo Gadung, Jakarta Timur Email: poppyrahayu.sabri@gmail.com

\section{Pengembangan Life Skill Perempuan dalam Kriya Tekstil Makrame}

DOI: $10.18196 /$ berdikari.v9i2.9589

\begin{abstract}
In general, housewives have a lot of free time that can be used for more effective activities. For this reason, it is necessary to strive for an activity that can be carried out by housewives that have economic value to provide additional family income. This community service activity aimed to improve skills of textile crafts for housewives who are members of the Integrated Entrepreneurship Development community. These skills are a provision for entrepreneurship so that members can have craft products and can market the results of the macrame crafts through an online shop. The service activity was carried out to facilitate housewives who have a strong desire to be able to help the family economy. The activity used the lecture method, learning by doing, and discussion. This training was guided by makrame craftsmen with the assistance of the committee. The service activity was carried out at the East Jakarta Creative Gathering Place. The result of this activity was that participants could make makrame bags and understand the marketing process through the online shop. This training received a positive response and assessment from the participants.
\end{abstract}

Keywords: makrame, entrepreneurship, online shop

\begin{abstract}
ABSTRAK
Pada umumnya, banyak waktu luang bagi ibu-ibu rumah tangga yang dapat dimanfaatkan untuk kegiatan yang bermanfaat. Untuk itu, perlu diupayakan suatu kegiatan yang dapat dilakukan oleh ibu-ibu rumah tangga yang bernilai ekonomi, sehingga diharapkan dapat memberikan tambahan pendapatan keluarga. Kegiatan Pengabdian Masyarakat ini bertujuan agar anggota komunitas Pengembangan Kewirausahaan Terpadu yang sebagian besar adalah ibu rumah tangga dapat memiliki keterampilan dalam kriya tekstil yang memadai sebagai bekal wirausaha dan dapat memasarkan hasil keterampilan makrame ini melalui online shop. Kegiatan ini dilakukan untuk memfasilitasi ibu rumah tangga yang memiliki keinginan kuat untuk dapat membantu ekonomi keluarga. Metode kegiatan menggunakan metode ceramah, learning by doing, dan tanya jawab. Pelatihan ini dipandu oleh Sabrina Munawaroh seorang pengerajin makrame dengan dibantu para panitia. Kegiatan dilaksanakan di Tempat Kumpul Kreatif Jakarta Timur. Hasil kegiatan ini adalah peserta dapat membuat makrame tas dan memahami proses pemasaran melalui online shop. Pelatihan ini mendapat penilaian dan respon positif para perserta sehingga dapat dikatakan berhasil.
\end{abstract}

Kata kunci: makrame, wirausaha, online shop 


\section{PENDAHULUAN}

Program Pengabdian pada Masyarakat adalah kegiatan wajib universitas yang melibatkan masyarakat luas yang diharapkan dapat memberikan skill tambahan dan manfaat kepada masyarakat melalui berbagai pelatihan, salah satunya, yaitu workshop. Pada 2019 Program Studi Pendidikan Bahasa Jepang Universitas Negeri Jakarta mengadakan workshop pembuatan makrame di Tempat Kumpul Kreatif, Gedung Pusat Promosi Industri Kayu dan Mebel, Pulo Gadung, Jakarta Timur. Kegiatan tersebut diikuti oleh komunitas Pengembangan Kewirausahaan Terpadu yang ingin mengembangkan diri untuk menambah life skill. Pelatihan makrame ini dilaksanakan agar peserta pelatihan yang merupakan masyarakat sekitar memiliki keterampilan dalam kerajinan kriya tekstil sehingga dapat menghasilkan produk fesyen yang berkualitas, yaitu tas.

Makrame sudah sering dilakukan manusia sejak mengenal kegiatan berlayar. Seiring dengan berjalannya waktu, makrame tidak hanya dilakukan untuk membuat jaring dan jala. Pada tahun 1970-an produk makrame dapat dipakai oleh manusia seperti topi, sarung tangan, kaos kaki, dan sebagainya (Chace, 1981). Teknik makrame termasuk teknik simpul tali sederhana yang bahan bakunya murah, mudah, serta tanpa alat mesin, tetapi memerlukan kreativitas yang tinggi. Selain itu, kerajinan ini dapat menghasilkan produk yang beragam, seperti tas, dompet, berbagai hiasan dinding, taplak meja, ikat pinggang wanita, dan sebagainya.

Anggota komunitas Pengembangan Kewirausahaan Terpadu sebagian besar adalah ibu rumah tangga yang memiliki keinginan dilatih dalam berwirausaha. Rata-rata kegiatan mereka adalah mengurus anak dan rumah tangga. Meskipun begitu, ibu rumah tangga memiliki dorongan yang kuat untuk dapat membantu ekonomi keluarga (Haryanto, 2008). Untuk itu, mereka menjadi sasaran dalam workshop ini agar peserta memiliki keterampilan dalam kriya tekstil yang memadai sebagai bekal wirausaha dan dapat memasarkan hasil keterampilan makrame melalui online shop. Produk makrame dipilih karena alat dan bahan yang digunakan murah dan keterampilan yang diperlukan hanyalah keterampilan simpul-menyimpul. Dalam hal ini, online shop dijadikan sebagai objek pasar yang dipilih karena di era digitalisasi online shop menjadi sarana wirausaha yang mudah, murah, dan dapat menjangkau konsumen secara luas. Namun, pada kenyataannya masih banyak ibu rumah tangga yang belum mengerti mengenai sistem online shop. Mereka cenderung masih menggunakan sistem penjualan konvensional (Juwariyah, 2019).

\section{METODE PELAKSANAAN}

Metode pelaksaan yang dirancang agar kegiatan workshop dapat berjalan dengan lancer, 
yaitu: 1) tahap perencanaan dan persiapan, 2) tahap pelaksanaan, 3) tahap evaluasi, dan 4) pelaporan kegiatan.

Tahap perencanaan dan persiapan, yaitu 1) melakukan koordinasi dengan Sabrina Munawaroh sebagai narasumber; 2) melakukan koordinasi dengan pengelola Tempat Kumpul Kreatif, Gedung Pusat Promosi Industri Kayu dan Mebel, Pulo Gadung Jakarta Timur sebagai tempat yang akan digunakan; 3) melakukan koordinasi dengan ketua komunitas Pengembangan Kewirausahaan Terpadu mengenai waktu dan lokasi workshop yang akan dilakukan; dan 4) mengadakan pelatihan makrame terlebih dahulu kepada mahasiswa yang menjadi panitia.

Tahap pelaksanaan workshop makrame bagi anggota komunitas Pengembangan Kewirausahaan Terpadu, yaitu 1) penyampaian informasi umum mengenai makrame oleh narasumber kepada peserta pelatihan; 2) peserta pelatihan melakukan praktik langsung dipandu oleh narasumber; 3) para mahasiswa yang telah bisa melakukan makrame melakukan monitoring setiap kelompok peserta pelatihan; 4) penyampaian materi mengenai pemasaran melalui online shop; dan 5) sesi tanya jawab antara peserta dan narasumber mengenai makrame dan pemasaran melalui online shop.

Tahap evaluasi dilakukan dengan memberikan angket kepada peserta pelatihan setelah tahap pelaksanaan selesai dilakukan. Peserta pelatihan mengisi angket untuk menilai kebermanfaatan pelatihan, menuliskan tanggapan, dan saran mengenai kegiatan workshop yang telah berlangsung.

\section{HASIL DAN PEMBAHASAN}

Makrame adalah kesenian tekstil klasik yang dibuat oleh para penenun Arab dengan teknik simpul-menyimpul menggunakan tali sejak abad ke-13. Kata makrame berasal dari kata mikramah yang berarti anyaman atau hiasan tangan. Berdasarkan sejarahnya, kegunaan makrame untuk menghindari kerumunan lalat pada hewan tunggangan milik orang-orang di Timur Tengah. Lubis (2018) mengatakan bahwa kesenian makrame sempat berjaya pada 1970-an. Perkembangannya pun menyebar ke wilayah Eropa dan Italia hingga dikenal di Inggris pada akhir abad ke-17.

Selama ini banyak pelatihan makrame dilakukan yang sasarannya adalah masyarakat. Beberapa pelatihan makrame yang telah dilakukan, yaitu pelatihan pembuatan makrame dompet dari kain perca di Panti Asuhan Muhammadiyah K.H. Achmad Dahlan Surabaya (Hidayati, 2013); pelatihan pembuatan makrame gantungan pot untuk ibu-ibu rumah tangga RT 08 RW 05 Kelurahan Cempaka Baru (Hakuma, 2018); dan pelatihan pembuatan makrame tas menggunakan tali kur dan nilon di Desa Binangun, Kabupaten 
Tuban (Wiratsiwi, 2018). Hasil dari ketiga pelatihan tersebut adalah keberhasilan para peserta yang antusias dalam membuat produk makrame. Perbedaan pelatihan kami dengan ketiga pelatihan sebelumnya adalah produk makrame yang dihasilkan, alat dan bahan yang digunakan, simpul yang digunakan, dan adanya tambahan tentang materi berwirausaha melalui online shop.

Dalam pelaksanaan kegiatan ini, hambatan yang muncul adalah ketidakpercayaan diri yang muncul dari para peserta workshop di awal kegiatan. Awalnya para peserta mengira bahwa menyimpul tali hingga menjadi sebuah barang merupakan hal yang sulit. Namun, narasumber dan para panitia berhasil meyakinkan para peserta dengan cara memandu peserta dengan baik dalam pembuatan makrame tas sehingga kepercayaan diri peserta meningkat dan mereka menikmati proses pembuatan makrame.

Hasil kegiatan Pengabdian pada Masyarakat ini adalah peserta pelatihan dapat membuat produk makrame berupa tas selempang yang terbuat hanya dari bahan tali katun dan keterampilan simpul yang sederhana. Selain itu, mereka dapat memahami bagaimana melakukan pemasaran melalui online shop, sehingga produk makrame yang dibuat dapat dipasarkan dan memberikan tambahan penghasilan untuk ekonomi keluarga.

\section{Makrame sebagai Life Skill}

Makrame tidak hanya sekadar kegiatan menenun, merajut, dan menyimpul tali secara repetitif, tetapi juga merupakan ajang atau wadah untuk menyatukan orang-orang dengan hobi yang sama. Mereka bersama-sama belajar kerajinan tangan, menjadi produktif, dan melakukan kegiatan yang bermanfaat yang dapat dilakukan semua kalangan.

Menguasai keterampilan makrame akan memunculkan banyak manfaat. Beberapa manfaat yang didapat oleh peserta, yaitu 1) life skill makrame dapat membantu dalam hidup karena seni makrame dapat menghasilkan barang yang dapat dipakai untuk keseharian seperti tas, ikat pinggang, dan barang lainnya; 2) memiliki keterampilan makrame akan mengasah soft skill di bidang kreativitas; 3) makrame mampu menunjang life skill yang jika terus diasah tidak hanya menghasilkan barang yang bisa dipakai, tetapi juga bisa dijual untuk menjadi bisnis; dan 4) referensi bagi pemilihan suatu keterampilan dalam membuat suatu kerajinan yang murah, mudah, dan tanpa alat/mesin, serta dapat dilakukan secara santai, tetapi tetap dapat menghasilkan produk yang beragam, memiliki berbagai fungsi, dan memiliki cita rasa seni. 


\section{5}

\section{Proses Pembuatan Makrame Saat Workshop}

Workshop dilaksanakan dalam satu hari, yaitu pada Selasa, 2 Juli 2020. Kegiatan dimulai pada pukul 08.31 WIB sampai dengan pukul 15.00 WIB. Kegiatan diawali dengan registrasi. Peserta menunggu di dalam ruangan workshop, di Tempat Kumpul Kreatif. Setelah kegiatan dibuka oleh MC dan narasumber telah memberikan informasi umum mengenai makrame, kegiatan selanjutnya adalah praktik langsung pembuatan makrame.

Alat yang digunakan, yaitu gunting dan gawang baju. Bahan yang digunakan oleh para peserta pelatihan adalah tali katun. Tali katun dipilih karena ukurannya yang tidak terlalu besar atau kecil, teksturnya tidak kasar, dan mudah disimpul oleh para pemula yang melakukan makrame.

Berikut merupakan proses pembuatan makrame yang dilakukan pada saat workshop berlangsung.

1. Panitia menyediakan alat dan bahan pembuatan makrame, yaitu gunting, gawang baju, dan tali katun. Gunting dan tali katun disiapkan sebanyak jumlah peserta. Panitia menggunting tali katun 40 meter yang dibagi menjadi 3 gulungan besar ukuran 12 meter, dan 1 gulungan kecil ukuran 4 meter. Gawang baju disiapkan masingmasing satu untuk setiap kelompok.

2. Pembentukan kelompok dan pendistribusian alat dan bahan diarahkan oleh $\mathrm{MC}$ dan narasumber. Satu kelompok maksimal terdiri atas 4 orang yang mengelilingi tiap sisi gawangan.

3. Setiap kelompok didampingi oleh satu panitia yang membimbing peserta agar terhindar dari kesalahan dalam menyimpul tali katun. Panitia membantu peserta mengikat tali pada gawangan kemudian dilanjutkan dengan satu teknik simpul berbentuk simpul kotak (square knot) yang dibuat saling berselingan dan terus dilakukan hingga kurang lebih tali tersisa sekitar $10 \mathrm{~cm}$. Bagian tali yang telah dibuat ini akan menjadi dasar tas tersebut.
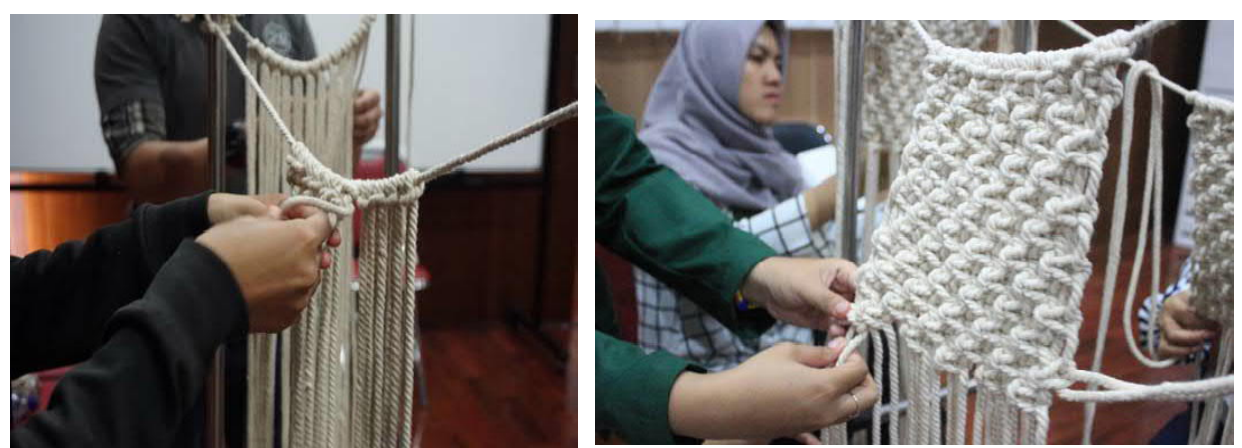

Gambar 1. Proses Awal Pembuatan Tas dengan Teknik Sqare Knot (Sumber:Dokumentasi P2M Pelatihan Makrame) 
4. Selanjutnya, peserta membuat bagian tali sling untuk tas menggunakan teknik simpul yang sama, yaitu square knot, tetapi dibuat memanjang dengan menggunakan 2 pasang tali berukuran pendek yang telah disiapkan panitia.

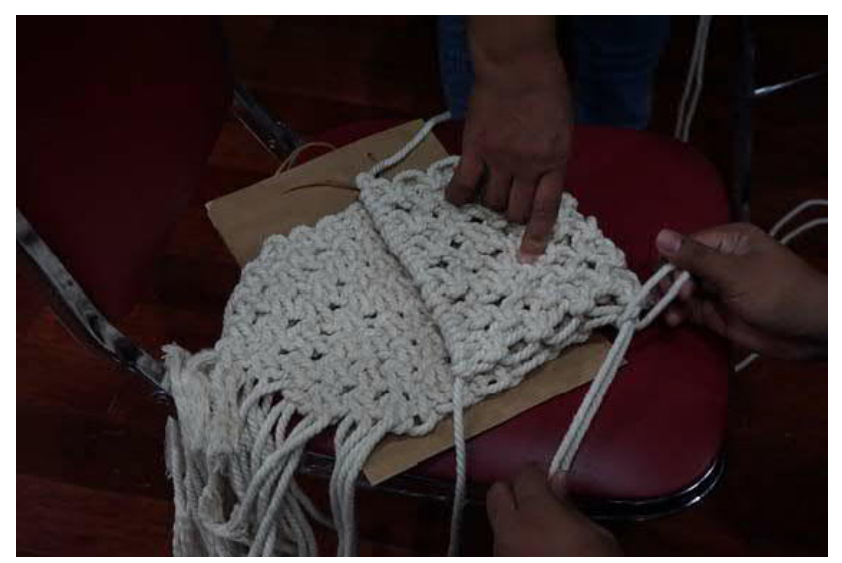

Gambar 2. Pembuatan Tali Sling untuk Tas (Sumber:Dokumentasi P2M Pelatihan Makrame)

5. Langkah terakhir, sisa tali sling dipotong menggunakan gunting sesuai dengan kebutuhan ataupun selera tiap peserta. Selanjutnya, jadilah tas makrame katun yang mudah dibuat, unik, memiliki nilai seni, dan berdaya guna. Para peserta pelatihan dipersilakan membawa pulang tas makrame ini.

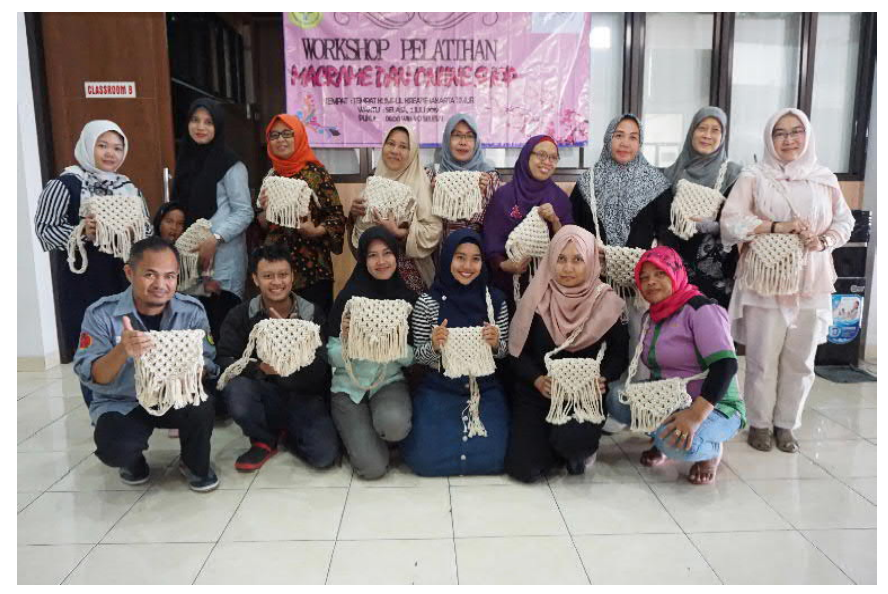

Gambar 3. Hasil Makrame Tas Peserta Pelatihan (Sumber:Dokumentasi P2M Pelatihan Makrame) 


\section{7}

Contoh-Contoh Kreasi Makrame

1. Makrame Tas

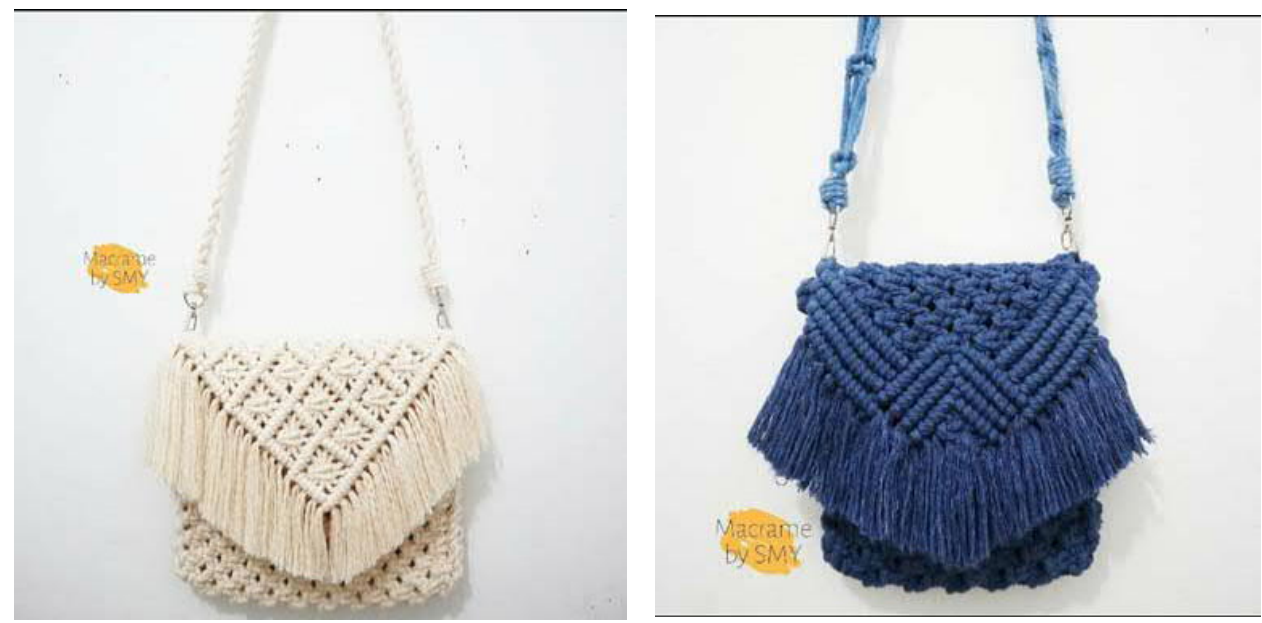

Gambar 4. Kreasi Makrame Tas

(Sumber:Instagram @macrame.by.smy)

Makrame tas merupakan produk makrame yang tidak hanya cantik, tetapi dapat digunakan dalam kegiatan sehari-hari. Warna, bahan tali, dan model tas dipilih sesuai kebutuhan orang yang membuatnya. Makrame tas dapat dipakai untuk berpergian santai ataupun berbelanja. Fungsinya tergantung pada model dan ukuran tas tersebut.

2. Makrame Gelang

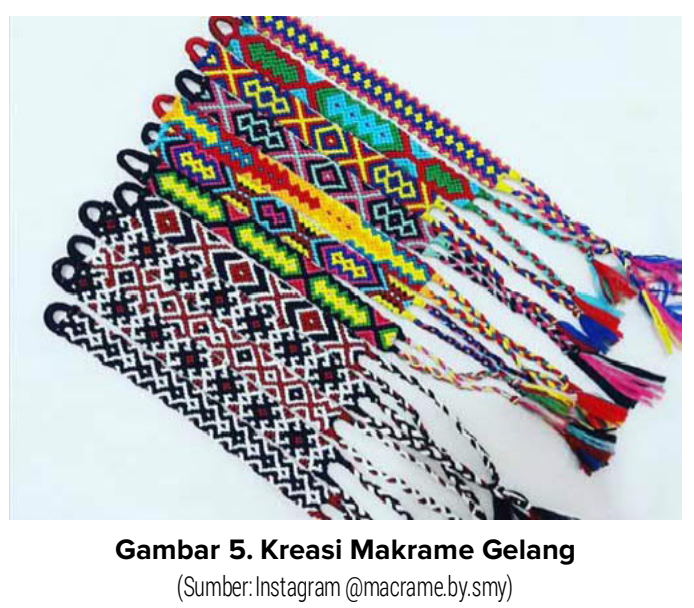

Makrame gelang seperti yang ditunjukan pada Gambar 4 merupakan salah satu aksesoris yang sederhana, tetapi dapat memperindah gaya busana. Bukan hanya wanita, melainkan juga pria dapat menggunakan makrame gelang. Dalam membuat makrame gelang, tali yang digunakan biasanya berukuran lebih kecil dari tali katun, seperti menggunakan tali kur yang memiliki bermacam warna. 
3. Makrame Gantungan Kunci

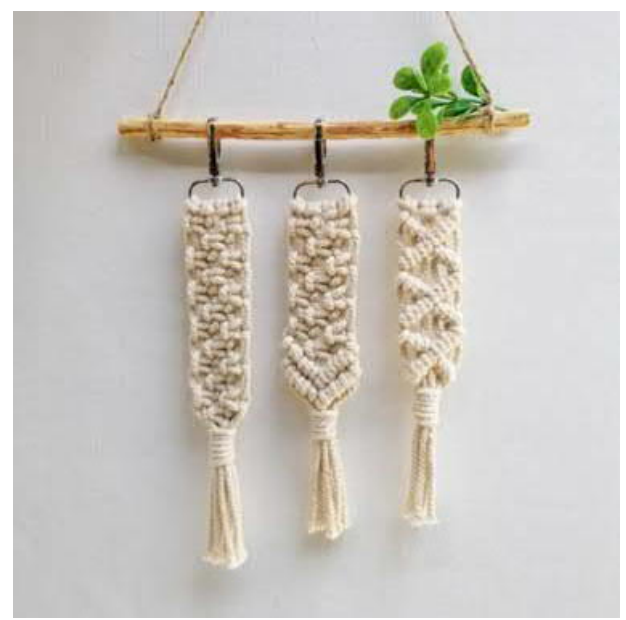

Gambar 6. Kreasi Makrame Gantungan Kunci

(Sumber:Instagram @macrame.by.smy)

Pada Gambar 5 makrame gantungan kunci dibuat menggunakan tali katun. Namun, tidak terbatas pada tali katun, pengrajin dapat berkreasi dengan jenis tali dan warna yang lain. Makrame gantungan kunci ini dapat dipasang di kunci, tas, ataupun tempat pensil.

4. Makrame Hiasan Dinding

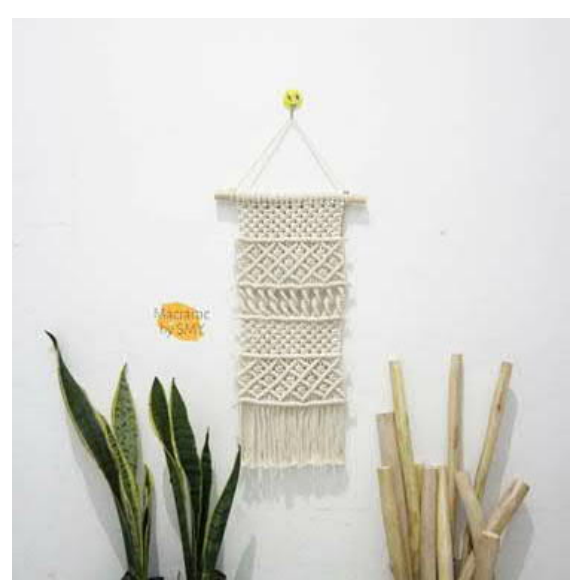

Gambar 7. Kreasi Makrame Hiasan Dinding (Sumber: Instagram @macrame.by.smy)

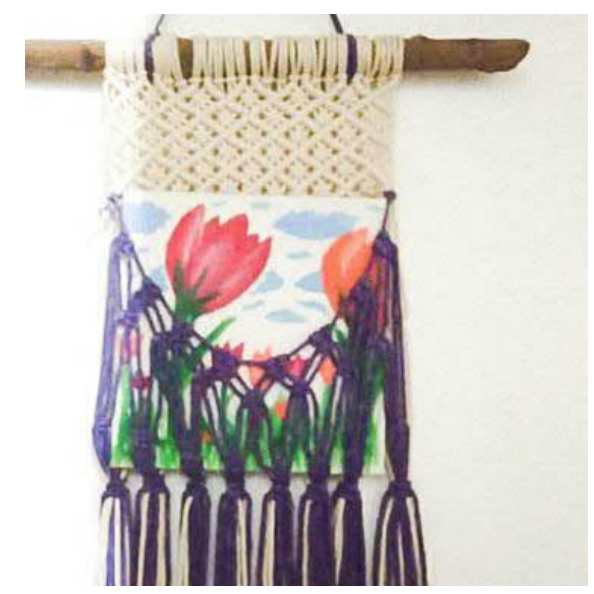

Gambar 8. Kreasi Makrame Hiasan Dinding (Sumber: Koleksi pribadi)

Makrame hiasan dinding dapat dijadikan sebagai dekorasi untuk memperindah interior ruangan. Berdasarkan modelnya, hiasan dinding ini dapat memiliki fungsi lain selain menjadi pajangan. Pada Gambar 6 makrame hanya digunakan sebagai hiasan dinding, sedangkan pada gambar 7 makrame tidak hanya menjadi hiasan dinding, tetapi dijadikan sebagai tempat menaruh lukisan. Bukan hanya lukisan, melainkan buku dan majalah pun dapat ditaruh, sehingga nilai fungsi makrame hiasan dinding tersebut bertambah. 


\section{9}

5. Makrame Kap Lampu

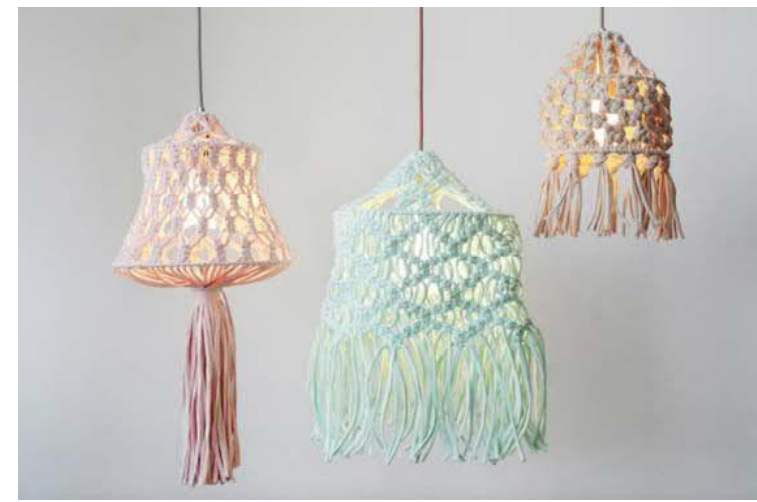

Gambar 9. Kreasi Makrame Kap Lampu

(Sumber:Instagram @macrame.by.smy)

Selain makrame dinding, makrame kap lampu pada Gambar 8 juga menjadi pilihan dalam mendekorasi rumah. Penggunaan makrame sebagai kap lampu dapat memperindah interior ruangan. Terlebih lagi, jenis tali dan warna pun dapat disesuaikan dengan selera pengrajin agar serasi dengan ruangan.

\section{Pemasaran Melalui Online Shop}

Kegiatan selanjutnya adalah materi berwirausaha dengan pemasaran melalui online shop. Pada materi ini dijelaskan bahwa di era industri 4.0 penggunaan teknologi dimaksimalkan. Tidak terkecuali pada bidang usaha kreatif. Kini telah banyak usahausaha yang mengandalkan perkembangan teknologi dan memanfaatkan media online sebagai tempat promosi. Pada kegiatan workshop, peserta pelatihan diberikan informasi mengenai keuntungan membuka usaha secara online. Pemasaran melalui media online memiliki banyak keuntungan, di antaranya memudahkan promosi untuk skala luas, memudahkan dalam berinteraksi dengan konsumen, dan tidak memerlukan tempat khusus untuk melakukan transaksi. Kerugian melakukan pemasaran melalui online shop juga diberitahukan, seperti mudahnya terjadi penipuan. Selain itu, peserta juga diberikan bekal pengetahuan bagaimana cara memulai dan melakukan pemasaran melalui media online agar menarik perhatian pembeli. Beberapa caranya, yaitu memiliki foto-foto produk yang bagus serta detail, membuat keterangan foto yang jelas, dan memiliki kemampuan meyakinkan konsumen dengan bahasa yang sopan dan menarik.

Berdasarkan hasil dari kegiatan pelatihan makrame yang telah dipaparkan, kegiatan workshop ini ditanggapi secara positif oleh para peserta. Para peserta, anggota komunitas Pengembangan Kewirausahaan Terpadu, sangat antusias menjalani kegiatan yang dipandu oleh narasumber dan dibantu oleh para mahasiswa sebagai panitia. Karena bahan yang 
digunakan murah dan mudah ditemukan, teknik menyimpul yang cukup mudah dipahami, serta penjelasan mengenai pemasaran melalui online shop memberikan ilmu yang dibutuhkan, para peserta menilai bahwa kebermanfaatan kegiatan sudah terasa dan menyarankan untuk kembali melakukan pelatihan serupa.

\section{SIMPULAN}

Berdasarkan uraian serta analisis pembahasan, disimpulkan bahwa kegiatan workshop makrame dan online shop kepada anggota komunitas Pengembangan Kewirausahaan Terpadu yang sebagian besar ibu rumah tangga sangat bermanfaat. Para peserta workshop menilai dan merespon positif dan antusias. Mereka mengikuti jalannya kegiatan workshop dari awal hingga akhir dan berhasil membuat produk makrame berupa tas serta memahami cara pembuatan dan pemasaran melalui online shop.

Anggota komunitas Pengembangan Kewirausahaan Terpadu diharapkan dapat berinovasi dalam menghasilkan berbagai produk makrame dan memasarkannya secara online. Selain itu, karena peserta memberikan respon positif terhadap pelatihan makrame ini, sebaiknya pelatihan makrame dilanjutkan ke tahap berikutnya, seperti membuat produk makrame dengan bahan dan simpul yang lain. P2M ini sebaiknya dilaksanakan dalam konsep masyarakat binaan.

\section{UCAPAN TERIMA KASIH}

Ucapan terima kasih ditunjukkan kepada pihak-pihak yang telah berkontibusi dalam pelaksanaan kegiatan P2M ini, yaitu kepada:

1. Lembaga Penelitian dan Pengabdian Kepada Masyarakat Universitas Negeri Jakarta,

2. Fakultas Bahasa dan Seni Universitas Negeri Jakarta,

3. Tempat Kumpul Kreatif Jakarta Timur atas penyediaan sarana dan prasarana yang dibutuhkan dalam kegiatan workshop, dan

4. Sabrina Munawaroh yang telah bersedia menjadi narasumber dalam pelatihan macramé.

\section{DAFTAR PUSTAKA}

Chace, S. 1981. Craft \& Hobbies: A Step by Step Guide to Creative Skills. USA: Reader's Digest. Harka, Ayu Zaskia. 2014. Teknik Makrame Menggunakan Benang Katun Untuk Budaya Pesta. Craft: Jurnal Tingkat Sarjana Bidang Senirupa dan Desain.
Hidayati, Elrysa Khoiril. 2013. Pelatihan Pembuatan Dompet Makrame dari Kain Perca di Panti Asuhan Muhammadiyah KH. Achmad Dahlan Surabaya. e-Jounal Edisi Yudisium. Vol. 02 No. 03, hlm. 130-138.

Hukama, La Diadhan. 2018. Pemberdayaan Ibu-Ibu 
Rumah Tangga Melalui Pelatihan Kerajinan Makrame dalam Membuat Benda Fungsional Gantung Pot. Wikrama Parahita: Jurnal Pengabdian Masyarakat.

Lubis, Devy. 2018. "Jelajah Dunia Macrame”, http:// m.harnas.co/2018/04/01/jelajah-dunia-macrame, diakses pada 13 September 2020 pukul 22:19 WIB.

Haryanto S. 2008. Peran Aktif anita dalam Peningkatan Pendapatan Rumah Tangga Miskin: Studi Kasus pada Wanita Pemecah Batu di Pucanganak Kecamatan Tugu Trenggalek. Jurnal Ekonomi Pembangunan, Vol. 9 No. 2, 216-227.

Wendri Wiratsiwi, Mega Puspita Sari, Lulu Anggi Rhosalia. 2018. Pelatihan Pembuatan Tas dengan Teknik Makrame dari Bahan Tali Kur di Desa Binangun Kecamatan Singgahan Kabupaten Tuban. SNasPPM Universitas PGRI Ronggolawe Tuban. Vol. 3, hlm. 501-504. 